\title{
Article
}

\section{Children's Participation in LAC Reviews: a study in one Engilsh local authority}

Pert, H, Diaz, C and Thomas, Nigel

Available at http://clok.uclan.ac.uk/11211/

Pert, H, Diaz, C and Thomas, Nigel ORCID: 0000-0002-5310-9144 (2014)

Children's Participation in LAC Reviews: a study in one Engilsh local authority.

Child and Family Social Work. ISSN 1356-7500

It is advisable to refer to the publisher's version if you intend to cite from the work.

http://dx.doi.org/10.1111/cfs.12194

For more information about UCLan's research in this area go to

http://www.uclan.ac.uk/researchgroups/ and search for < name of research Group>.

For information about Research generally at UCLan please go to

http://www.uclan.ac.uk/research/

All outputs in CLoK are protected by Intellectual Property Rights law, including

Copyright law. Copyright, IPR and Moral Rights for the works on this site are retained by the individual authors and/or other copyright owners. Terms and conditions for use of this material are defined in the policies page.

\section{CLoK}

Central Lancashire online Knowledge www.clok.uclan.ac.uk

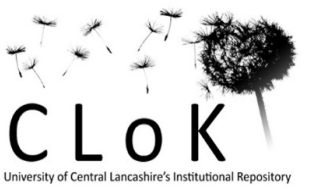




\title{
Children's Participation in LAC Reviews:
}

\section{a study in one English local authority}

\author{
Hayley Pert, Clive Diaz \\ (People \& Communities Department, Bath \& North East Somerset Council) \\ Nigel Thomas \\ (School of Social Work, University of Central Lancashire) \\ Correspondence to: \\ Nigel Thomas \\ Professor of Childhood and Youth Research \\ The Centre for Children and Young People's Participation, \\ School of Social Work \\ University of Central Lancashire \\ Preston PR1 2HE \\ npthomas@uclan.ac.uk
}




\title{
Children's Participation in LAC Reviews: a study in one English local authority
}

\begin{abstract}
Although the law in England and Wales requires a child's wishes and feelings to be heard in LAC (Looked After Children) reviews, there remains limited research into how far this is achieved. This study interviewed 25 children and 16 foster carers to explore how well children understand and take part in reviews, and what factors impede this. The study found that levels of participation, as experienced by children and foster carers, were very low and the methods used relatively ineffective. Children experienced significant barriers in engaging with the review process. The article concludes that, as a vehicle of children's participation, LAC reviews are still not working well, and calls for more attention to the views of children and young people and to the effectiveness of LAC reviews.
\end{abstract}

\section{Keywords}

Looked after children, child care policy and practice, independent reviewing officers, children's participation, advocacy for children.

\section{List of Abbreviations}

LA - Local Authority

IRO - Independent Reviewing Officer

\section{Introduction}

The participation of children has seen a dramatic shift in the last few decades (Lansdown, 2010) and it is now widely recognised as essential to involve children in decisions made about their lives. This is particularly pertinent for looked after children, who are part of many more decisions and decision making forums than their peers (Thomas and O'Kane, 1999). Article 12 of the Convention on the Rights of the Child clearly sets out the right of children to be heard in decisions which affect them. The UK, as a signatory, is obliged to uphold the child's right to express views and have them taken into account. This does not imply a right to make decisions or be part of the decision making process (Schofield and Thoburn, 1996); however, it does arguably represent a shift from regarding children as 'objects of concern' (ButlerSloss, 1988) to viewing them as citizens with human rights (Cashmore, 2002). 
Section 22 of the Children Act 1989 requires that local authorities consider the wishes and feelings of looked after children when making decisions or reviewing care plans, which they are required to do regularly. Under the Adoption and Children Act 2002, local authorities are required to ensure that every looked after child has an Independent Reviewing Officer (IRO) who is tasked with ensuring that reviews are properly conducted and that the child is able to play a meaningful part in the process. The Children and Young Persons Act 2008 extended the responsibilities of the IRO with regard to care planning and performance monitoring. This was further strengthened by the Care Planning, Placement and Case Review Regulations (England) 2010 and the statutory guidance in the IRO Handbook (DCSF 2010).

There are particular arguments for the participation of looked after children, in a context where the number and type of decisions made are very different to those of other children - for example, decisions about where a child lives, and with whom (Thomas and O'Kane, 1999). Empowering children to participate in these decisions is particularly important in ensuring that their needs are fully understood, aside from the positive effects of participation in terms of confidence and self-esteem, invaluable when preparing looked after children for independence (Bostock, 2005).

The largest study to consider children's participation in review meetings was by Thomas and O'Kane (1999). Similar research has not been carried out since the role of the IRO was introduced. Thomas and O'Kane found that only half of children interviewed attended their review meetings, and those who did frequently found them 'boring' or 'scary'. Other research has suggested that children have limited understanding of the purpose and content of their reviews (Munro, 2001) and that preparation and choice are both lacking (Sinclair, 1998). A common theme (Thomas, 2011) is that children feel disillusioned with the review process and that their views are not listened to. 'Most report that the purpose of the meeting is to talk about, rather than to, them' (Munro, 2001: 9).

A traditional model of participation is Hart's (1992) ladder, with a series of levels that range from tokenism to profound engagement. More recent theorising has focused on the importance of dialogue, dialogic space and mutual recognition (Thomas, 2007; Graham and Fitzgerald, 2010; Mannion, 2010; Thomas, 2012). Children's participation includes not just what a child says and what notice is taken, but also how well the child understands the issues, the options available and the reasons for decisions; also how much say the child has over the time and place of the meeting and whether s/he has a free choice to attend or not (Thomas, 2000, 2002; Shier, 2001; Pölkki et al., 2012). There is widespread agreement that a key determinant of children's participation, especially in professional services, is the commitment of adults to supporting it (Welsby, 1996; Shemmings, 2000; Thomas, 2000, 2002; Bessell and Gal, 2009; Vis et al., 2010; Pölkki et al., 2012; Bijleveld et al., 2013). There is also evidence that that participation in matters concerning them is very 
significant to children in care, although they do not always want be active participants in meetings (Pölkki et al., 2012).

A series of national web-based surveys by the Children's Rights Director for England explored children's views of IROs (Ofsted, 2011a) and corporate parenting (Ofsted, 2011b) and made brief mention of LAC reviews. Respondents had little understanding of the role of the IRO; only $17 \%$ felt that the IRO listened to them. Similarly, Ofsted (2013) recently explored the efficacy of the IRO role through interviewing a small sample of children across ten Local Authorities alongside IROs and parents. Findings indicated a general dissatisfaction amongst children with LAC reviews and a feeling that IROs were not fulfilling their role in supporting participation. Most recently, NCB conducted a national study of IROs in England (Jelicic et al. 2014). The results suggest that IROs have in some cases enabled children to take a fuller part in the process, but that 'the reality varied considerably, and while there were examples reflecting the kind of good practice envisaged in the IRO Handbook ... there was also considerable evidence that insufficient time was allowed to support children to meaningfully participate in the review' (p. 45). Recent court judgments have also pointed to ineffective IRO practice, including failure to ascertain, understand and take into account children's views (S v Rochdale Metropolitan Borough Council [2008] EWHC 3282 Fam; A and S v Lancashire County Council [2012] 1689 Fam).

It is therefore timely for research to examine whether children's views of reviews have changed since the IRO role has been introduced.

\section{The research}

The research reported here, conducted in one local authority in England was designed to bring together the perspectives of children and young people and their foster carers in addressing the following questions:

1. How far do looked after children understand the process and purpose of LAC reviews?

2. How do looked after children feel about their meetings, and how far do they believe that their wishes and feelings are taken into consideration within LAC reviews?

3. What are the barriers to looked after children participating in and engaging with the review process?

Using a purposive sampling method, children and young people were recruited who had attended at least one LAC review within the local authority. Children and young people were identified using the agency's database and they and their foster carers received invitations to participate. The target age range was 8-17 years, to include roughly equal numbers of boys and girls, some sibling groups, and a mix of ethnicities representative of the local area. Ethical approval was given by The University of 
Bristol. Participants were provided with information about the research in easy-toread and pictorial format; this was revisited ahead of interviews and all were asked to sign consent forms.

All interviews took place in the foster placement. To ensure meaningful participation regardless of age or ability, children and young people were offered a choice of methods by which to participate. This included the use of pictures to act as visual representations of reviews. Participants who chose to use these methods, were encouraged to draw the format of their reviews and how they felt about them. Most younger children chose to use these more creative methods (for examples see Appendix); for many this acted as a prompt for fuller discussion. Within the general research topic, each participant was enabled to discuss the topics that mattered most to them This allowed them to include or exclude issues that may have been personally sensitive.

Feedback sessions with internal and regional IROs, social work teams and senior managers were held upon completion of the study. The purpose of this was to provide further insight into the findings and to test out suggestions for improvements in services.

Twenty-five children and young people were interviewed: 11 children (8-12 years) and 14 young people (13-17); 13 girls and 12 boys; five from a minority ethnic background; 13 placed together with siblings. The average length of time looked after was three years (range eight months to nine years). Sixteen foster carers were also interviewed, 14 female and two male; all were White British and had been approved carers for between two and 16 years.

Interviews were audiorecorded (with participant permission), transcribed and analysed (along with drawings and pictures which children produced or used in interviews). Responses from children, young people and foster carers were analysed together and the following broad themes identified:

1. Children's feelings and understanding of reviews

2. Benefits of LAC reviews

3. Preparation for $L A C$ reviews

4. Foster carers as resources

5. The role of professionals

In what follows 'children' refers to those aged up to 12, and 'young people' to those aged 13 and over; 'children and young people' refers to the whole group.

\section{Children's feelings and understanding of reviews}

Almost all children and young people (23) knew that they had review meetings regularly. However, their understanding of the purpose of reviews varied widely: 
'They are to check up on me' (young woman aged 14)

'I think it's to do with school' (boy aged 8)

'They are to see how things are going' (boy aged 10)

None of the children and young people interviewed suggested that meetings were to review care plans or make decisions, although one child did suggest that review meetings were to look forward to the next six months. Participants had mixed feelings about their reviews: eight children said that they felt ' $O K$ ' about their meetings but nine found them too long and boring. Just two felt that meetings were positive:

'I like the meetings, I like to have a chat and it's nice to talk about me' (boy aged 10)

Of the young people, none reported enjoying their meetings. Some young people reported stronger feelings of embarrassment or anger:

'The meetings themselves are a bit scary, they are a bit daunting really, so then I'm not in the right frame of mind to talk about anything and it's just...embarrassing' (young man aged 15)

Young people were also more vocal in expressing wishes not to attend, with specific reasons for not doing so.

For the majority of children and young people the content of the meetings was repetitive, boring and generalised - lacking in individuality:

'It's just tell us about school, how's school? Tell me about your health, are you happy? Tell me about this....' (young woman aged 13)

Whilst children and young people were clear that they did not enjoy their meetings, all 25 attended their reviews. They spoke with a sense of resignation about doing so:

'They are OK because.... well they happen. Everything is boring but they have to be done' (young woman aged 16)

Participants reported using strategies to ensure that reviews ended more quickly. Some simply agreed with everything that was said; some disengaged, physically leaving the room, and others spoke as little as possible:

'I just sit, I don't say anything. It's weird, I just want them out of the way' (young man aged 13)

\section{Benefits of LAC reviews}

How useful children and young people found their LAC reviews was linked to their understanding of the purpose of reviews, even when this understanding was limited. For example, adolescents made comments about the value of LAC reviews when they had a specific practical task or issue they wished to resolve: 
'They are helpful in a way because you can put your point across about anything you might want to change. If you didn't have them then you wouldn't know who to see or what to do and nothing would be changed' (young woman aged 16)

Conversely, adolescents who had some knowledge of the purpose of reviews often saw little value in them. Specifically this was linked to how settled they felt they were in placement and how long they had been 'in care':

'I've been with $X$ and $Y$ (foster carers) for 8 years so it's not really like I need all of that. I don't really need anything. The sooner it comes, the sooner it's over.' (young man aged 16)

In terms of the long-term benefits of LAC reviews, children and young people felt largely detached from any tangible positive or negative effect upon their lives. Only two participants could remember any action points or goals. Adolescents particularly felt disassociated from the outcomes of their LAC review, with high levels of either dissatisfaction or apathy:

'What's the point? Nothing ever changes so there is no point' (young woman aged 16)

Foster carers found review meetings useful. Many commented that they welcomed a forum to raise action points and ensure that the professionals acted on them. Foster carers were clear, however, that the children they cared for appeared to gain nothing from the meetings themselves:

'Personally I don't think the children get a lot out of the reviews, I think they do in the sense that I make sure what we agree actually happens and the goals are then met' (foster carer of boy aged 11 and young woman aged 17)

Many foster carers felt that the review meetings were superficial, focusing on routine questions about health or education. Foster carers noted that action points around therapeutic intervention were subject to drift and that this was unchallenged by IROs. Significantly, there was little mention of the purpose of meetings in relation to updating care plans in preventing drift and meeting the child's long-term needs:

'I've been to probably 20-30 LAC reviews and nobody has ever turned and said 'Have you got a copy of the care plan? Has the care plan been updated?' (foster carer of young women aged 13 and 16)

Foster carers also queried the possible long-term negative effects of attending reviews, suggesting that having the meetings made children feel different:

'They don't attend; they don't like meetings at all. Their feeling is why should we have meetings? We want to be normal kids, why do we have all this paperwork, why do we have to talk to all these people?' (foster carer of girl aged 8 and young women aged 14 and 17) 


\section{Preparation}

Only two younger children reported that their social worker visited them before the review to ask them what they would like to talk about. None of the children interviewed made mention of their IRO visiting them between reviews.

A small number of children and young people recalled being asked to contribute to the agenda via a form sent in the post. Adolescents particularly disliked these forms, commenting that they were repetitive with little consideration of age or maturity. Aside from the use of forms, none of the children and young people interviewed could remember being asked what they would like to talk about at their review. Similarly, none of the children or young people interviewed could recall being offered, on a regular basis, choice in where and when to hold the review:

'It's always after school when I'm tired and everyone else is going to the shops and hanging out and that and I'm like oh, I've got to go home.... but they stop work at 5 so it has to be then, doesn't it? I'd have it on Sunday morning at 9 am and make them get up early!' (young man aged 16)

When asked where they would like to hold their review meetings, 15 suggested alternative venues, including McDonalds, Alton Towers and a bowling alley.

Lack of choice and control in who attended reviews was the most emotive topic for children and young people. One child counted nine adults at her last review, and when asked whom she would like at her next review, she removed four people. This was not unusual; only eight felt comfortable with who attended their LAC reviews:

'At my last review random people starting turning up and I was like, who are you? I didn't know who they were, it was crap' (young man aged 16)

Many children and young people felt confused about who attended their review meetings. In particular, this was raised in relation to foster carers' social workers. Younger children often could not remember these people's names, and suggested that they would not have them at the meeting if they had the choice. One group of siblings thought the foster carer's social worker was their foster carer's friend.

The presence of birth parents at review meetings was of huge importance to both children and young people and foster carers. Children and young people whose parents attended LAC reviews felt much more positively about them. Meanwhile foster carers felt less positive about the attendance of parents, with a feeling that the child was distracted or less engaged because of their presence:

'Sometimes I think the IRO misses important stuff because their mother is there, she adds nothing and makes it all about her. If she wasn't there then we could actually make the meetings about the kids' (foster carer of boy aged 11 and young woman aged 16) 


\section{Foster carers as resources}

The role of foster carers within reviews was highlighted as of importance to children and young people. Children and young people reported that they did feel listened to by the IRO in meetings. However, only three participants said they asked questions or initiated discussion in the LAC reviews; the majority reported that the IRO led the discussion and that the child or young person's agreement (or disagreement) was then sought. Children and young people suggested that their foster carer was key to their voices being heard:

'She helps me to say things because....well, it's difficult... he [IRO] ... speaks lots and then asks, do you want that? She (foster carer) will push me to speak up' (young woman aged 17)

Foster carers also reported feeling responsible for ensuring their foster child's wishes were heard and considered. This is not a simple task: foster carers noted that children could present as quiet and 'difficult' to engage within their LAC reviews; many suggested that their foster child might engage more if meetings were less professional-centred:

'Honestly I'm not sure what they (IROs) could do, it's hard, but they could invest more time planning things instead of going through the motions. There has got to be a better way of doing it' (foster carer of boy aged 9)

Whilst many foster carers recognised that as a forum of 'participation' the review meetings were lacking, as a 'professionals' meeting they were considered to be imperative. The foster carers interviewed clearly valued a forum in which to discuss areas for change or challenge with social workers, and felt responsibility for ensuring that their foster child's needs were accurately considered:

'It's always me pushing and pushing. I know they think I'm difficult, so it's hard-because I'm left with [ foster child] at the end of the day, so I need to make sure we all get it right.' (foster carer of boy aged 9)

\section{The role of professionals}

Children and young people were largely positive about their IROs. ${ }^{1}$ Younger children spoke of IROs playing games with them or taking them out for milkshakes as being memorable. However, six children and young people did not know who their IRO was or what their role was other than to chair the meetings. It is possible that this could be due to multiple staff changes during the interview period. However, other children and young people were dissatisfied with the social work service they had received and

\footnotetext{
${ }^{1}$ Participants were asked about the various professionals involved in their reviews. Most mentioned IROs; where they did not, they were prompted.
} 
with the IRO response. None had considered making formal complaints; foster carers felt that there was little evidence of the IRO promoting this. Examples were given of cases where there had been extensive drift, with actions carried over multiple review meetings. Foster carers felt that not enough was done between reviews to ensure that progress was made. The starkest example was of a child who reported having had eight social workers in three years, with extremely sporadic visits. The foster carer felt that this had not been challenged and the child reported feeling 'forgotten'. Similar examples of social workers visiting children at three-month intervals were commonplace, alongside those who would only visit children at contact sessions:

'She [social worker] comes when she feels like it! [When foster child] brought it up with her they had a big row... it's been an action point on the agenda for what feels like years now and it's really not fair' (foster carer of girl aged 8 and young women aged 15 and 17)

Some children reported having positive relationships with their social workers. Where children felt that they had got to know their social worker as a 'real person' and not just a professional they felt much more positively about them and the social work team generally:

Child: She is quite funny really! It's just normal, I don't know like, ummm... like when she comes and we do Xbox or Wii...

Interviewer: So you like it that she comes and plays computer games

Child: Yeah, I do... it's a good thing that she comes really because things are better now, better than before' (boy aged 9)

Those children who reported having positive relationships with their social worker also reported less negative feelings about review meetings, suggesting that the social worker-child relationship is important in how the child engages with the review process. The converse also applies: one foster carer reported that her foster children disliked their social worker so much that they hid from her. This would certainly impede the social worker's ability to prepare these children for reviews, and possibly affect the children's attendance at their LAC reviews.

The use of the advocacy service was limited (three children and young people), although many did report being offered an advocate and choosing not to use this service. Those who did, reported some difficulties in sharing information between social care, the IRO and the advocate:

'She [advocate] came, talked to the children and I thought great, that's done but then she didn't come to the review so I thought well where are the children's views? We've lost them. She [IRO] said nothing.' (foster carer of girl aged 8 , boy aged 8 and girl aged 10 . 


\section{Discussion}

It should be noted that this study presents the views of service users from one LA; no claims of national representativeness are made. It also focused on the views of service users, specifically children and young people and foster carers. This presents a useful, if partial, view of LAC reviews; research that also explored the perspectives of IROs, social workers and parents would be beneficial.

In discussing the findings we return to the three original research questions.

\section{How far do looked after children understand the process and purpose of LAC reviews?}

The results of this study would suggest that the children and young people interviewed had a basic understanding of why they had LAC reviews and what their purpose was. Results were categorised as 'basic understanding' (19) or 'inaccurate' (4). Inaccuracies were exclusive to younger children, suggesting the need for explanation in a manner appropriate to their age. This is in line with earlier and more recent research (Thomas and O'Kane, 1999; Ofsted, 2011a; Ofsted, 2013).

All the children in this study were invited to and attended their LAC reviews, and yet their understanding of the purpose was very limited. This raises the question whether continued attendance at LAC reviews, when they are not understood, is of use to children and young people. This study also found that attendance at reviews was not always an active choice for children and young people, particularly when they reported not understanding the process and feeling negatively about them. A significant proportion of children and young people reported attending reviews because they 'had to'. The view of review meetings as 'necessary' and part of life in the care system could serve to oppress already vulnerable children and young people and exacerbate feelings of being different.

Furthermore, those children who had only a basic understanding of the purpose of reviews reported greater feelings of scrutiny and unsurprisingly felt more negatively about reviews. This accords with literature on the role of professionals in enabling or obstructing participation (Vis et al, 2010) and of children's views of child protection case conferences (Cossar et al, 2011). Not understanding the process was raised by children and young people as a barrier to participation. This study supports this finding with a link made between lack of understanding of the process of reviews and dissatisfaction with reviews themselves.

An alternative, perhaps more cynical, view would be that these children and young people had correctly identified the actual, bureaucratic, purpose of LAC reviews as practiced by some professionals, in distinction to the official purpose as set out in legislation and guidance. 
2. How do looked after children feel about their meetings, and how far do they believe that their wishes and feelings are taken into consideration within LAC reviews?

Despite the multitude of legislative, policy and guidance frameworks that exist to promote the involvement of children in decision making, research paints a bleak picture of children and young people being dissatisfied with the levels of participation offered to them (Barnes, 2012; Ofsted, 2013). This study supports this, but also provides evidence that children felt listened to during their meetings, if not as part of the wider process of these meetings.

Taking LAC reviews to be a process and not a single event (Sinclair, 1998; DCSF, 2010; Thomas, 2011), children and young people reported being offered little opportunity to input their views at most stages of this process. This was most acutely felt in the planning and preparation stages of the LAC review process. This study supports earlier findings that children do not feel adequately prepared for reviews (Munro, 2001). Children and young people were also clear that the IRO came with an agenda; there was little sense that they could have a say in what was discussed, or other aspects of the process. This has implications for their self-confidence (Bostock, 2005); it is imperative that social workers and IROs try to promote the selfdetermination of an already vulnerable group (The College of Social Work, 2013). Better preparation of children and young people before their LAC review is necessary (Sinclair, 1998) and more emphasis should be placed upon social workers and IROs to ensure that this happens.

The environment and context of the LAC review, or any decision-making forum, is of importance in promoting the participation of children and young people (Cashmore, 2002; Murray and Hallett, 2000). This study supports earlier findings that children and young people were given little choice in who would attend or when or where the LAC review would be held (Sinclair, 1998; Thomas and O'Kane, 1999; Munro, 2001). In this way, a significant opportunity to encourage the participation of children and young people in decision-making is being lost, despite the IRO Handbook providing guidance in this area. Children and young people were forthcoming with suggestions of how they might change various contextual factors around their LAC reviews such as timing, location, how often they were held and in particular, choice of who would attend LAC reviews. A key finding was that children and young people wished for fewer people, particularly professionals, to attend their reviews. What this suggests is that an approach which emphasises on-going consultation with children and young people in how their LAC reviews are held would be more successful at encouraging participation.

Thomas et al. (1999) produced a package of materials to support practice in this area, including a set of picture cards as a stimulus for conversation with a child about topics for discussion, produced as an alternative to the LAC consultation booklets with which children and carers had expressed dissatisfaction. These packages were 
supplied to all agencies in Wales and Scotland, but there is little indication that they have been taken up in England.

Children and young people in this study reported that the IRO listened to them during meetings, in contrast to other research (Ofsted, 2011b). However, a number of young people thought that their reviews were not beneficial to them. It may be that these young people were not made aware of the actions or outcomes of their reviews, engendering a sense of apathy and dissatisfaction. Younger children did not experience the same levels of dissatisfaction, or were less engaged in the subject matter of reviews and so with the action points. This difference in opinion between younger children and adolescents is not unusual. Munro's study (2001) also referred to greater levels of dissatisfaction among adolescents. We know that adolescents can be more critical than younger children (Beckett and Taylor, 2010). What is interesting is that professionals had made greater efforts to be creative in reviews held for younger children. Younger children spoke of reviews which involved going out for milkshakes, whilst adolescents were expected to join in normal meetings, probably with the view that they would wish to be treated in a more adult manner. However, the results of this study suggest that it may be worth exercising the same, if not greater, levels of creativity with adolescents. This could go some way to improving how far they engage with and feel listened to as part of the LAC review process. Greater emphasis upon IRO visits between reviews, as suggested by the IRO Handbook, could undoubtedly assist with this.

Children and young people's attendance at LAC reviews was highlighted as a significant area for improvement in previous research (Thomas and O'Kane, 1999). All interviewees in this study attended at least part of their LAC reviews. This suggests that improvements have been made since the role of the IRO was introduced in 2002, although the suggestion that this is a result of IRO practice cannot be made on the basis of findings from this study. Perhaps a direct consequence of the improved attendance of children and young people in their LAC reviews is the potential attendance of their parents. Thomas and O'Kane (1999) found that children were less likely to participate in their LAC review if their parents had a challenging relationship with the LA. In this study, parental attendance was a significant issue for both children and young people and foster carers. Children and young people whose parents did not attend their LAC reviews were clear that they would like them to; for a significant number of children interviewed this had been requested and not granted. It is difficult to disentangle whether parents chose not to attend, or whether the IRO or LA had blocked this request. Nonetheless, this was an area in which children and young people reported feeling that their views had not been taken seriously or considered. This was supported by foster carers, who reported that children and young people were not offered the opportunity to consider who might attend their reviews and that parents were regularly requested to attend and this did not always happen. 


\section{What are the barriers to looked after children participating in and engaging with}

the review process?

Children and young people in this study were clear that review meetings were long and boring; only two children enjoyed their reviews; both described them being individual, creative and memorable with just the child and IRO present. All the other children and young people, whose reviews were held with many professionals present (up to nine was not unusual), felt the meetings did not include them and were boring; they saw them as essentially a meeting for adults.

Foster carers agreed (all 16). They suggested that the benefit to children and young people came from professionals taking action post-review. This accords with earlier research ( Sinclair, 1998; Thomas and O'Kane, 1999; Munro, 2001) in which authors report children finding LAC reviews to be adult-centric, albeit focussed upon the child. The important point here is that whilst professionals find LAC reviews of use in helping them fulfil their role toward the child, children and young people may feel like outsiders in a meeting of professionals. Perhaps it is time to consider how possible it is to carry out LAC reviews in a manner which is child-friendly and also fulfils the required statutory functions.

Looking back at Hart's (1992) ladder of participation, few children in this study were offered a genuine opportunity to influence any aspect of the meeting - suggesting rung 5 (consulted and informed) rather than rung 6 (adult-initiated, shared decisions with children). This was manifest in how their views were sought through the use of forms which were experienced as unsatisfactory, and also in how the meetings were carried out. Inadequate choice, control and lack of information have been highlighted as significant barriers to child and young person participation (Murray and Hallett, 2000; Cashmore, 2002; Hill, 2006; Thoburn, 2010). These results are perhaps related to the tension between protection and participation in social work practice (Shemmings, 2000). In feedback sessions with professionals and foster carers, it was evident that professionals did try to protect children from adult conversations, including decision-making forums. IROs suggested that children struggled to understand significant decisions and that often teenagers did not want to participate. This is not supported by research which emphasises the desire of children and young people to participate in decisions about their care (Murray and Hallett, 2000;

Cashmore, 2002; Thoburn, 2010). The strength of feeling from the participants in this study confirms that children and young people do not enjoy not being part of adult centric decision-making forums. Reviews were enjoyed when they were more child friendly, where they had choice in how they were run and in which they did not feel embarrassed or overwhelmed (Bostock, 2005; Thoburn, 2010). It is logical to expect that when children enjoy decision-making forums, they may be more likely to engage with them. Furthermore, children and young people in their feedback sessions agreed that reviews could be more 'fun' and would be of more use if they had greater ownership of them. 
The lack of perceived action following reviews is also a significant finding. Foster carers reported extensive drift, with actions carrying over across multiple reviews. This study found that only two children and young people interviewed could recollect any action points or goals from their LAC reviews. This disassociation with the potential benefit of the LAC review process, coupled with apathy about change, suggests that children and young people do not believe that the LAC review is useful to them; this accords with previous research in this area (Thomas, 2011). This is thus a significant challenge for IROs and social care staff to ensure that children and young people engage in decisions made about their lives.

Children and young people demonstrated limited understanding of the IRO role. This builds upon research drawn upon in the literature review (Ofsted, 2011a; 2011b). The study by the Children's Rights Director (Ofsted 2011a) demonstrated that children had some understanding of the role of the IRO in chairing meetings and reviewing their care plan. A quantitative study using multiple-choice answers, it is possible that this does not wholly reflect the true understanding of those children interviewed. The children and young people interviewed in the present study did not understand key task functions of the IRO role: namely challenging poor social care practice and ensuring that children's wishes and feelings are taken into account. Furthermore, the foster carers interviewed within this study raised concerns that IROs allowed actions to drift and gave stark examples of poor social care practice going unchallenged. This draws parallels with recent Ofsted (2013) research into the IRO's ability to challenge, in which the same LA was inspected. Findings were consistent with this study in that IROs demonstrated ineffective challenge. Our study suggests that a lack of understanding by children of the IRO role, coupled with a lack of effective challenge by the IRO, are important barriers to children and young people engaging with and participating in their LAC reviews.

\section{Conclusion}

The aim of this study was to explore service users' perspectives of LAC reviews. The views of children and young people and their foster carers were strikingly similar to the conclusions of research from 15 years ago. Little appears to have changed with regard to children and young people's views of the efficacy of reviews in 'hearing' their voice, despite the introduction of the IRO role and a plethora of guidance reinforcing the participatory focus of LAC reviews.

The lack of engagement reported by interviewees around all aspects of their review meetings suggests that children feel that meetings are done to them rather than with them. It is clear that foster carers value LAC review meetings as an opportunity to discuss and review key aspects of the child's life. In this sense, a key function of the review is being met. However, it appears that the participation of children is still taking second place to a procedural approach that prioritises statutory requirements, 
that despite a plethora of guidance and the introduction of the IRO little has fundamentally changed, and that decisions about their care are not being effectively informed by the views of children and young people.

\section{References}

Barnes, V. (2012) Social work and advocacy with young people: rights and care in practice. The British Journal of Social Work 42 (7), 1275-1292.

Beckett, C. and Taylor, H. (2010) Human Growth and Development. London: Sage Publications Ltd.Bessell, S. and Gal, T. (2009) Forming Partnerships: The Human Rights of Children in Need of Care and Protection. International Journal of Children's Rights 17, 283-298.Bijleveld, G., Dedding, C. and Bunders-Aelen, J. (2013) Children's and young people's participation within child welfare and child protection services: a state-of-the-art review, Child and Family Social Work

Bijleveld, G., Dedding, C. and Bunders-Aelen, J. (2013) Children's and young people's participation within child welfare and child protection services: a state-ofthe-art review, Child and Family Social Work (first published online 4 July 2013 | DOI: $10.1111 /$ cfs.12082).

Bostock, L. (2005) Improving the lives of fostered children and young people, $C C$ Inform [online]. Available at: $<$ http://www.ccinform.co.uk/articles.aspx?liArticleID254> [Accessed 22 June 2013].

Butler-Sloss, E. (1988) Report of the Inquiry into Child Abuse in Cleveland 1987. London: HMSO.

Cashmore, J. (2002) Promoting the participation of children and young people in care. Child Abuse and Neglect. 26, 837-847.

Cossar, J., Brandon, M. and Jordan, Peter. (2011) 'Don't Make Assumptions' Children's and Young People's Views of the Child Protection System and Messages for Change. Office of the Children's Commissioner. Norwich: CRCF.

Department for Children, Schools and Families (2010) IRO Handbook: Statutory guidance for independent reviewing officers and local authorities on their functions in relation to case management and review for looked after children. London: HMSO.

Graham, A. and Fitzgerald, R. (2010) Progressing children's participation: Exploring the potential of a dialogical turn. Childhood, 17(3), 343-359.

Hart, R. (1992) Children's Participation: from Tokenism to Citizenship. Florence: UNICEF Innocenti Research Centre. 
Hill, M. (2006) Children's voices on ways of having a voice: children's and young people's perspective on methods used in research and consultation. Childhood $\mathbf{1 3}$ (1), 69-89.

Jelicic, H., La Valle, I. and Hart, D. (2014) The role of Independent Reviewing Officers (IROs) in England: Final report. NCB, London.

Lansdown, G. (2010) 'The realisation of children's participation rights: critical reflections', in Percy-Smith, B. and Thomas, N. (eds) A Handbook of Children and Young People's Participation: Perspectives from Theory and Practice. London: Routledge.

Mannion, G. (2010) 'After participation: The socio-spatial performance of intergenerational becoming', in Percy-Smith, B. and Thomas, N. (eds) A Handbook of Children and Young People's Participation: Perspectives from Theory and Practice. London: Routledge.

Munro, E. (2001) Empowering looked-after children. Child and Family Social Work 6, 129-137.

Murray, C. and Hallett, C. (2000) Young People's Participation in Decisions Affecting Their Welfare. Childhood 7 (1), 11-25.

Ofsted (2011a) Children on Independent Reviewing Officers. A report of children's views by the Children's Rights Director for England. London: Ofsted. Available at: < http://www.ofsted.gov.uk/resources/childrens-views-independent-reviewingofficers $>$ [Accessed 27 December 2012].

Ofsted (2011b) Having Corporate Parents. A report of children's views by the Children's Rights Director for England. London: Ofsted. Available at: <http://www.ofsted.gov.uk/resources/having-corporate-parents> [Accessed 2 January 2013].

Ofsted (2013) Independent Reviewing Officers: taking up the challenge? [pdf]. London: Ofsted. Available at: <http://www.ofsted.gov.uk/resources/Independentreviewing-officers-taking-up-the-challenge $>$ [Accessed 23 June 2013].Pölkki, P., Vornanen, R., Pursiainen, M. and Riikonen, M. (2012) Children's Participation in Child-protection Processes as Experienced by Foster Children and Social Workers, Child Care in Practice 18(2), 107-125.

Pölkki, P., Vornanen, R., Pursiainen, M. and Riikonen, M. (2012) Children's Participation in Child-protection Processes as Experienced by Foster Children and Social Workers, Child Care in Practice 18(2), 107-125.

Schofield, G. and Thoburn, J. (1996) Child Protection: The voice of the Child in Decision Making. London: IPPR.

Shemmings, D. (2000) Professionals' attitudes to children's participation in decision making: dichotomous accounts and doctrinal contests. Child and Family Social 
Work 5, 235-243.

Shier, H. (2001). Pathways to participation: Openings, opportunities and obligations. A new model for enhancing children's participation in decision-making, in line with Article 13.1 of the UNCRC. Children \& Society 15(2), 107-117.

Sinclair, R. (1998) Research Review: Involving children in planning their care. Child and Family Social Work 3, 137-142.

The College of Social Work. (2013). Code of Ethics. [online] Available from: http://www.tcsw.org.uk/uploadedFiles/TheCollege/Members_area/CodeofEthicsAu g2013.pdf [Accessed 06 June 2013].

Thoburn, J. (2010) Looked after children- care planning, placement choice, and review, Community Care Inform [online] Available at:

http://www.ccinform.co.uk/guides/looked-after-children-care-planning-placement-choiceand-review/ (accessed 28/10/2014).

Thomas, N. (2000, 2002) Children, Family and the State: Decision-making and Child Participation, Basingstoke: Macmillan; Bristol: Policy Press.

Thomas, N. (2007) Towards a theory of children's participation, International Journal of Children's Rights 15(2), 199-218.

Thomas, N. (2011) Care planning and review for looked after children: fifteen years of slow progress?, British Journal of Social Work 41(2), 387-398.

Thomas, N. (2012) Love, rights and solidarity: studying children's participation using Honneth's theory of recognition, Childhood 19(4), 453-466.

Thomas, N. and O'Kane, C. (1999) Children's participation in reviews and planning meetings when they are 'looked after' in middle childhood. Child and Family Social Work 4, 221-230.

Thomas, N., Phillipson, J., O'Kane, C. and Davies, E. (1999) Children and Decision Making: a training and resource pack. University of Wales Swansea, International Centre for Childhood Studies (now obtainable from npthomas@uclan.ac.uk).

Vis, S.A., Holtan, A., and Thomas, N. (2010) Obstacles for child participation in care and protection cases: why Norwegian social workers find it difficult. Child Abuse Review (21), 21-43.

Welsby, J. (1996) 'A voice in their own lives' in De Boer, W. (ed.) Children's Rights in Residential Care in International Perspective. Defence for Children International, Netherlands. 


\section{Children's Pictures and Drawings}

The table in this picture represents the LAC review, while the stick figures represent who currently attends this child's LAC review.

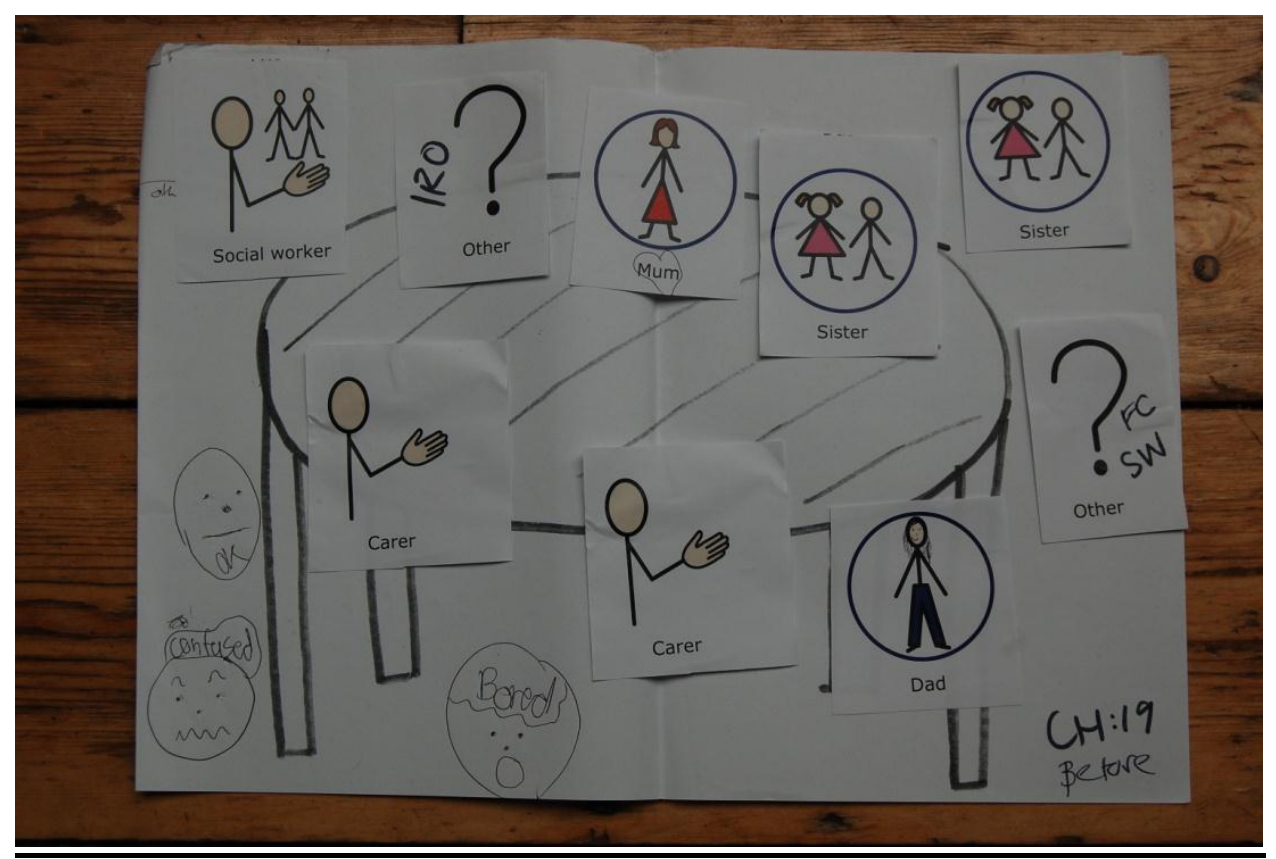

The child was then asked if they would like to add or remove anyone from the table for their next LAC review.

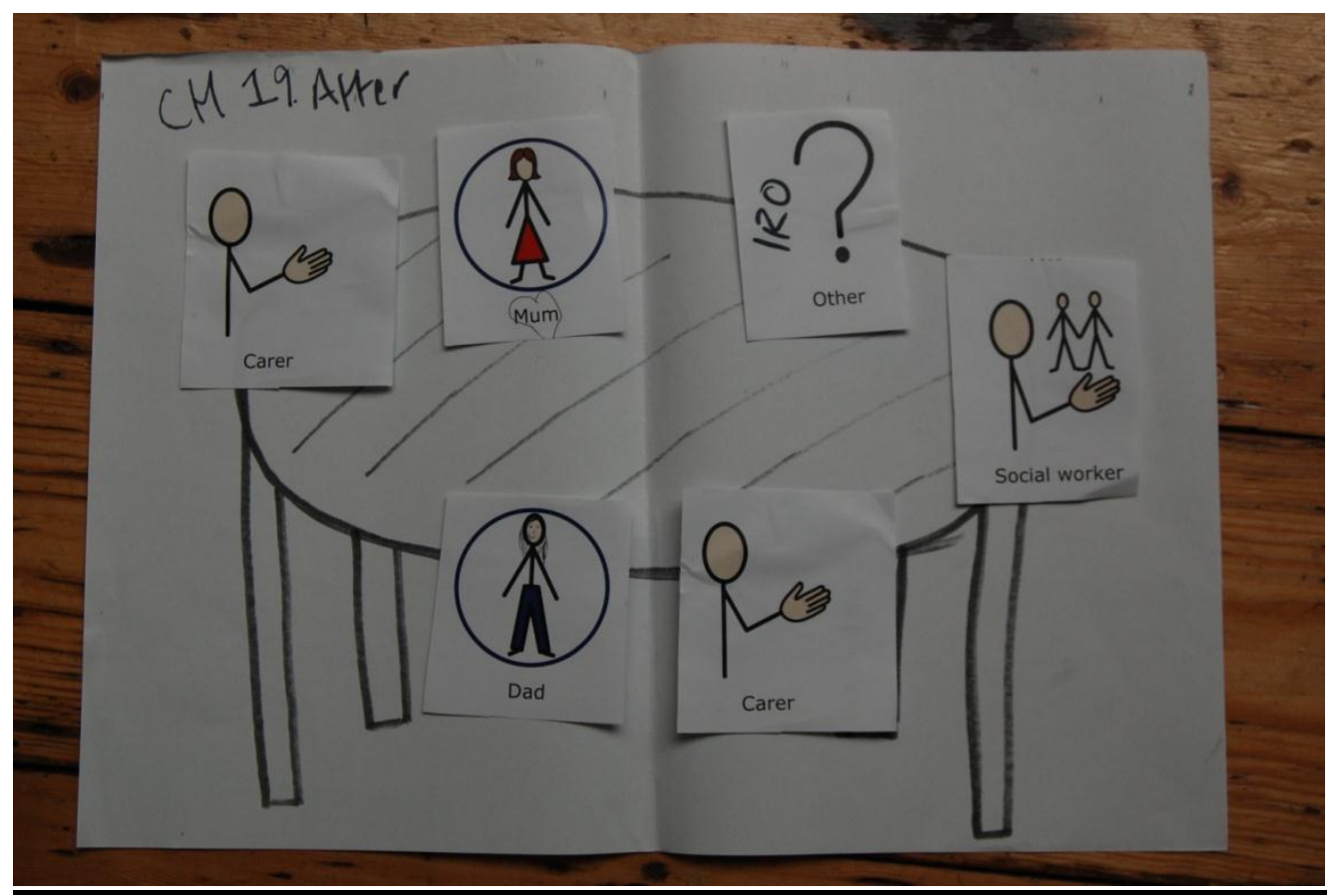


Child drawings: feelings about $\mathrm{LAC}$ reviews
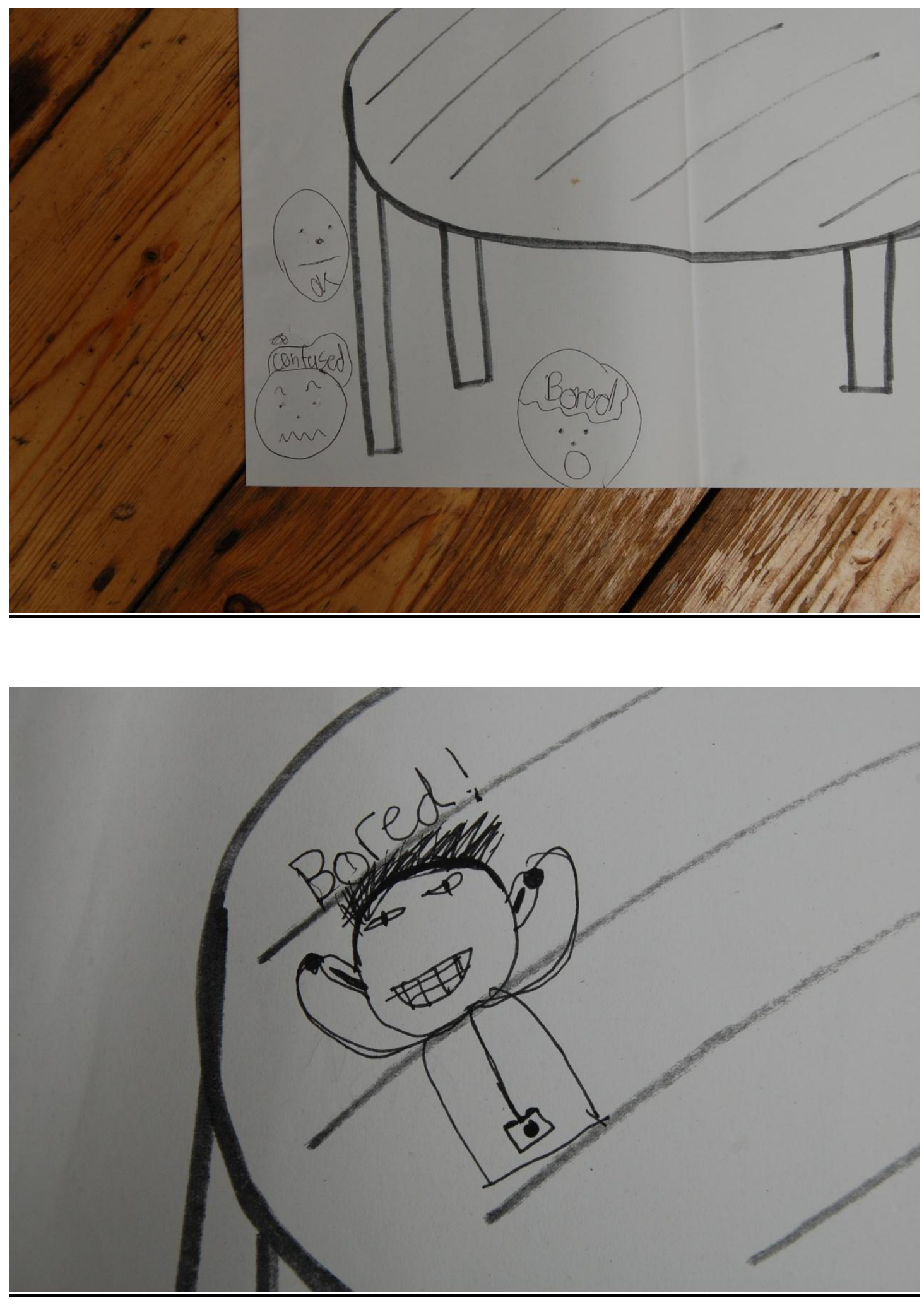